LA-UR-01-6526

Approved for public release; distribution is unlimited.

\section{Title: Thermal Stability of Self-Supported Metallic Multilayered Thin Films}

Author(s):
Submitted to:
http://lib-www.lanl.gov/la-pubs/00796506.pdf H. Kung and R.G. Hoagland 


\section{Thermal Stability of Self-Supported Metallic Multilayered Thin Films}

A. Misra, H. Kung and R.G. Hoagland, Materials Science and Technology Division, MS G755, Los Alamos National Laboratory, Los Alamos, NM 87545

\section{ABSTRACT}

The morphological stability and strength retention following elevated temperature exposure or thermal cycling will be crucial in exploiting the extremely high strengths of nanolayered materials in advanced engineering applications. The effects of elevated temperature $\left(\leq 800{ }^{\circ} \mathrm{C}\right)$ vacuum annealing on the morphological stability and mechanical properties of sputter deposited $\mathrm{Cu}-\mathrm{Nb}$ multilayers with $75 \mathrm{~nm}$ bilayer period are reported here. Even after $800^{\circ} \mathrm{C} / 1$ hour anneal, the continuity of the layered structure is maintained and the bilayer periods are unchanged. The in-plane grain sizes in both $\mathrm{Cu}$ and $\mathrm{Nb}$ coarsened but were anchored at grooved boundaries preventing further growth. For a constant bilayer period, the effect of increasing the in-plane grain size on the multilayer hardness is found to be insignificant. After annealing, the layers are observed to be offset by shear along a vertical plane at the triple point junctions that have equilibrium groove angles aligned in a zig-zag pattern. A new mechanism is proposed for the evolution of this "anchored" structure that is resistant to further morphological instability.

\section{INTRODUCTION}

Multilayered thin films on substrates are used in a variety of applications such as x-ray mirrors, magnetic recording media and heads, diffusion barrier coatings, wear resistant coatings, etc. Thermal stability of these films has been studied mostly for the instability mechanisms involving interdiffusion in miscible layers, chemical reaction to form a new phase/compound or phase transformation (e.g., amorphous to crystalline), etc. Recent studies have shown that metallic multilayers, composed of alternating layers of soft metals, typically possess unusually high strengths when the bilayer periods are on the order of a few to a few tens of nanometers $[1,2]$. In addition to coatings on substrates, these high-strength metallic multilayers may also have applications as self-supporting components.

Most studies of the morphological stability of fiber or lamellar composites have been conducted for materials where the microstructural features are on the micron-scale. These studies show that although lamellar composites are relatively more stable than fiber composites, significant morphological instabilities may still occur in layered materials such as pearlitic steels, $\gamma / \alpha_{2}$ titanium aluminides, rolled Ni-W, etc [3,4]. Recently, Josell and Spaepen [5] have studied the stability of near-micron scale multilayered films, primarily through creep testing, and observed layer pinch-off due to grain boundary grooving as a major instability mechanism. These studies indicate that complete degradation of the multilayer structure is often possible during short anneals at elevated temperatures. Clearly, more detailed studies of the thermal stability of nano-scale multilayers are needed to elucidate the mechanisms of morphological instability and identify microstructure design schemes towards stable structures.

In this investigation, we have studied the morphological stability of self-supported, room temperature sputtered nano-scale $\mathrm{Cu}-\mathrm{Nb}$ multilayered films in the temperature range of $500-$ $800{ }^{\circ} \mathrm{C}$. $\mathrm{Cu}$ and $\mathrm{Nb}$ do not form any intermetallic compounds, there is insignificant mutual 
solubility and no phase transformations at the annealing temperatures chosen. The microstructural evolution and hardness changes following annealing are reported here.

\section{EXPERIMENTAL PROCEDURES}

$\mathrm{Cu}-\mathrm{Nb}$ multilayers with equal $\mathrm{Cu}$ and $\mathrm{Nb}$ layer thicknesses (throughout this article, the samples are identified with their layer thickness which is one-half of the bilayer period) of $75 \mathrm{~nm}$ were sputter deposited on glass or $\mathrm{Si}$ substrates at room temperature. Sputtering was dc magnetron with 4 mTorr Ar pressure, $10 \mathrm{~cm}$ substrate-to-target distance and $100 \mathrm{~W}$ and $200 \mathrm{~W}$ power applied to $10 \mathrm{~cm}$ diameter $\mathrm{Cu}$ and $\mathrm{Nb}$ sputtering targets respectively. The chamber was evacuated to a base pressure of $\sim 2 \times 10^{-8}$ torr prior to deposition. The total number of bilayers deposited was 50, resulting in a total sample thickness of $7.5 \mu \mathrm{m}$. After deposition, the multilayered films were peeled from the substrates and the self-supported samples subjected to 1 hour annealing at temperatures of 500, 600, 700 and $800{ }^{\circ} \mathrm{C}$ under vacuum of $\leq 1 \times 10^{-7}$ torr. Microstructures were studied by cross-section transmission electron microscopy (TEM) using a Philips CM30 microscope at $300 \mathrm{kV}$. Hardness and modulus of the films, epoxy-bonded to Si substrates after annealing, were measured with a NanoIndenter II using the continuous stiffness method. The indentation depths were in the range of 0.25 to $0.5 \mu \mathrm{m}$.

\section{RESULTS}

\section{$\underline{\text { As-synthesized Microstructures }}$}

The microstructure of the asdeposited $\mathrm{Cu}-\mathrm{Nb} 75 \mathrm{~nm}$ multilayer is shown in Fig. 1(a) as a cross-section bright field (BF) TEM micrograph, along with the selected area diffraction pattern (SADP) in Fig. 1(b). Note the nanocrystalline structure of the layers with columnar grains, i.e., most grain boundaries are normal to the interface. The in-plane grain size is on the order of the layer thickness $(75 \mathrm{~nm})$ for $\mathrm{Cu}$ and slightly lower for $\mathrm{Nb}$. The SADP indicates a $\{110\}$ bcc // $\{111\}$ fcc // interface plane texture in these multilayered films.

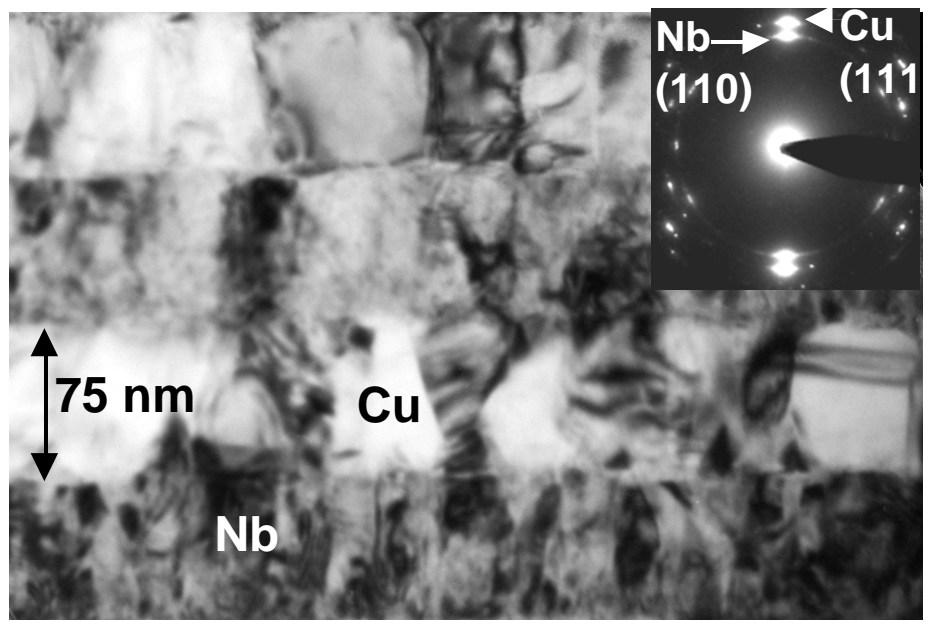

Fig. 1 BF TEM micrograph and the corresponding SADP showing the textured polycrystalline microstructure, in cross-section, of the as-deposited $\mathrm{Cu} / \mathrm{Nb}$ multilayer.

\section{$\underline{\text { Annealed Microstructures }}$}

Keeping the initial layer thickness fixed at $75 \mathrm{~nm}$, the microstructural evolution following 1 hour anneals at 600,700 and $800{ }^{\circ} \mathrm{C}$ is shown in Fig. 2(a)-(c) respectively. Some significant features after $600{ }^{\circ} \mathrm{C}$ anneal are (Fig. 2(a)): (i) layer structure is not disintegrated (i.e., no significant geometric rearrangement of the layered structure), (ii) no measurable change in the 75 $\mathrm{nm}$ layer thickness, and (iii) in-plane grain size has increased. Perhaps the most significant feature is that at some regions, (e.g., the region marked by arrows in Fig. 2(a)), the grain 
boundaries in $\mathrm{Cu}$ and $\mathrm{Nb}$ are aligned along a vertical line. The significance of this observation is discussed later in the paper. From other images not shown here, most grains in the $\mathrm{Nb}$ layer were observed to be $\sim 75-100 \mathrm{~nm}$ while most grains in the $\mathrm{Cu}$ layer were $\sim 150-200 \mathrm{~nm}$ after $600{ }^{\circ} \mathrm{C}$ anneal. The $\{110\} \mathrm{Nb} / /\{111\} \mathrm{Cu}$ texture was retained after annealing.

Fig. 2(b) shows the microstructure of the $\mathrm{Cu}$ $\mathrm{Nb}$ multilayered film after $700{ }^{\circ} \mathrm{C} / 1 \mathrm{~h}$ anneal. Even at $700{ }^{\circ} \mathrm{C}$, no disintegration of the layered structure or any coarsening of the bilayer period is detected. The most significant microstructural change is the facetted appearance of grain boundaries and offsets between layers along an approximate vertical plane with an attending shear effect of the layers along this plane. These planes where shear offsets are observed presumably coincide with the regions shown in Fig. 2(a) where grain boundaries in $\mathrm{Cu}$ and $\mathrm{Nb}$ appeared to have aligned. The grains in both layers are approximately equal in size and typically, $~ 375-$ $400 \mathrm{~nm}$ wide.

Fig. 2(c) shows the microstructure of the $\mathrm{Cu}$ $\mathrm{Nb}$ multilayered film after $800{ }^{\circ} \mathrm{C} / 1 \mathrm{~h}$ anneal. Even at a temperature of $\sim 80 \%$ of the melting point of $\mathrm{Cu}$, the layer structure is maintained. Also, no significant coarsening of the layers is observed. Thermal stresses, upon cooling, have led to significant dislocation activity in both layers. The in-plane grain sizes are similar to $700{ }^{\circ} \mathrm{C}$ indicating that increasing the anneal temperature from 700 to $800{ }^{\circ} \mathrm{C}$ did not significantly accelerate grain growth. In fact, places where layers are offset along a vertical plane serve as "anchor" points thereby limiting further grain growth. Once again, faceted grains at triple or quadruple points are observed. However, the layer offsets are about the same as after $700{ }^{\circ} \mathrm{C}$, indicating that nearequilibrium groove angles are formed at triple points and continued grooving to split the layers does not occur.

The equilibrium groove angle is related to the grain boundary $\left(\gamma_{\square \square}\right)$ and interface energies $\left(\gamma_{\text {int }}\right)$ as follows (Fig. 3):

$\gamma_{\square \square}=2 \gamma_{\text {int }} \cos \theta$
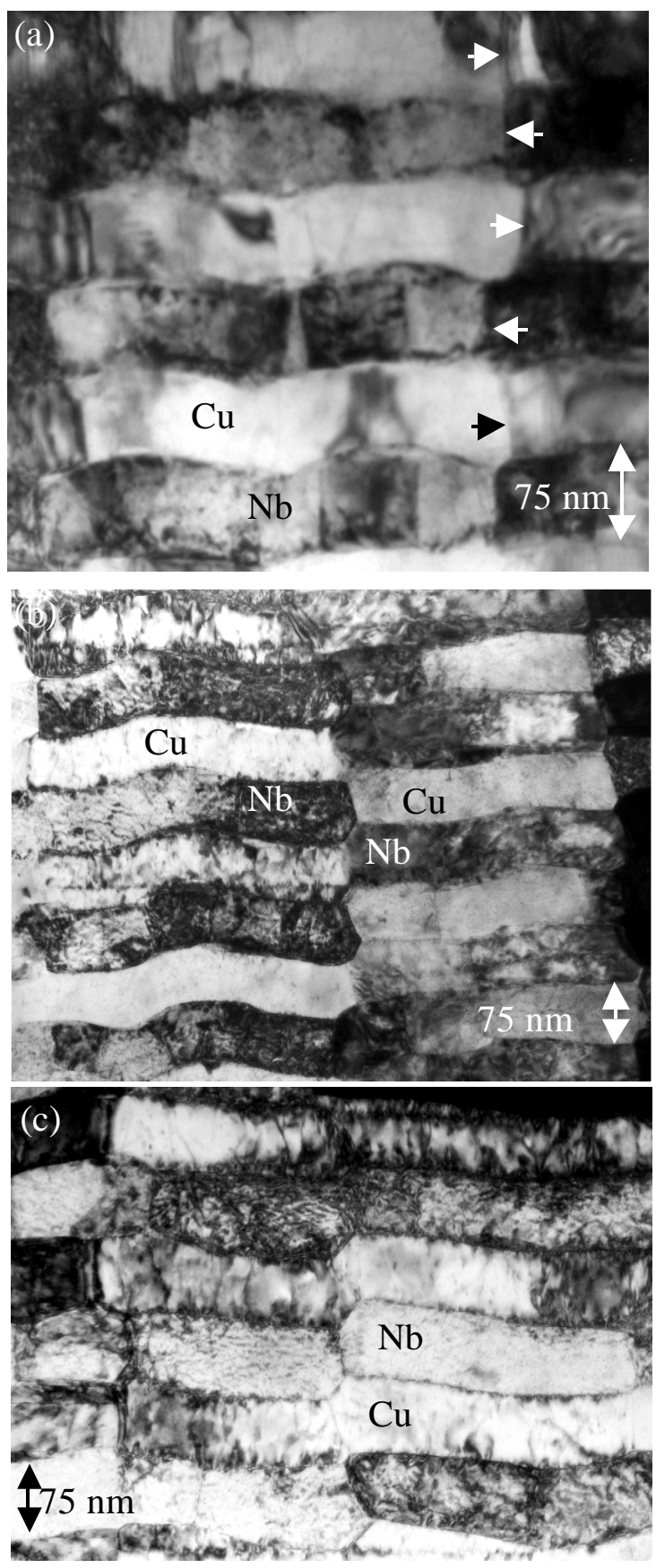

Fig. 2 BF TEM micrographs showing the cross-sectional views of the microstructures of $75 \mathrm{~nm} \mathrm{Cu}-\mathrm{Nb}$ multilayers after (a) $600 ; \mathrm{C}$, (b) $700 ; \mathrm{C}$, and (c) $800 ; \mathrm{C}$ anneals. Note the alignment of grain boundaries along a vertical line (marked with arrows in (a)), and grooving and shear of layers at triple points in (b). 
where $\theta$ is one-half the groove angle. The $\mathrm{Nb}-\mathrm{Nb}$ grain boundary makes an angle of $120^{\circ}$ with the two adjoining $\mathrm{Cu}-\mathrm{Nb}$ interfaces. Hence, $\gamma_{\mathrm{Nb}-\mathrm{Nb}} \approx \gamma_{\mathrm{Cu}-\mathrm{Nb}}$. Similarly, $\mathrm{Cu}-\mathrm{Cu}$ grain boundaries made angles of $126-130^{\circ}$ with the $\mathrm{Cu}-\mathrm{Nb}$ interfaces, indicating that $\gamma_{\mathrm{Cu}-\mathrm{Cu}} \approx \tilde{\square} \tilde{\square} \gamma_{\mathrm{Cu}-\mathrm{Nb}}$.

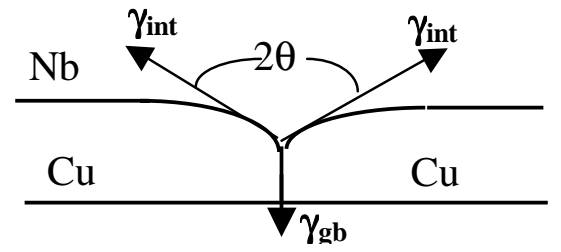

\section{$\underline{\text { Multilayer Hardness }}$}

The hardnesses of the $\mathrm{Cu}-\mathrm{Nb} 75 \mathrm{~nm}$ multilayer before and after annealing are compared in Fig. 4. In the as-deposited state the hardness was $3.4 \pm 0.3 \mathrm{GPa}$. After annealing at different temperatures in the range of $500-800{ }^{\circ} \mathrm{C}$, no significant change in either the hardness or the modulus was observed. These results indicate that the increase in the in-plane grain size does not affect the hardness of these multilayers. Thus, the hardness enhancement generally observed with decreasing layer thickness in the $\mathrm{Cu}-\mathrm{Nb}$ multilayers [1,2] is primarily due to the resistance to slip transmission from the $\mathrm{Cu}-\mathrm{Nb}$ interfaces, with a relatively smaller contribution from the in-plane grain boundaries. This observation is consistent with atomistic modeling of nanolayered metals that indicates that these materials derive their strength from the transmission of single dislocations across the interphase interfaces [6].

\section{DISCUSSION}

Thickness perturbations (Rayleigh

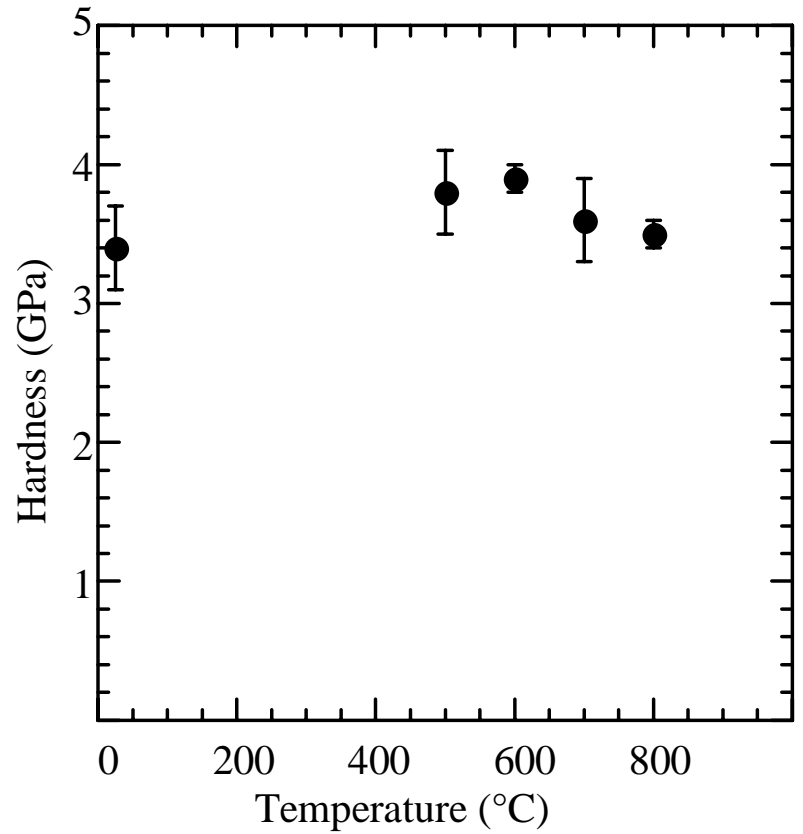

Fig. 4 Hardness of $75 \mathrm{~nm} \mathrm{Cu} / \mathrm{Nb}$ multilayers as a function of annealing temperature. Note the insignificant change in hardness with annealing.

Fig. 3 Schematic showing the force balance at a triple point that determines the equilibrium groove angle. $\operatorname{Cos} \theta=\gamma_{\mathrm{gb}} / 2 \gamma_{\text {int }}$. instability [7]) that lead to spheroidization of rods embedded in a matrix are common in fiber composites. Spheroidization of lamellar composites is a two-step process (plates to rods, and then rods to spheres) and hence, the plate morphology is likely to resist spheroidization better than rods [8]. Typically, morphological instability in a lamellar structure starts at the edge of a finite plate (i.e., lamellae termination points) embedded in a matrix. Since there are no lamellae termination points in the thin film multilayers investigated here, any morphological change during annealing is expected to initiate with thermal grooving at triple points (intersection of inplane $\mathrm{Cu}-\mathrm{Cu}$ or $\mathrm{Nb}-\mathrm{Nb}$ grain boundaries with the $\mathrm{Cu}-\mathrm{Nb}$ interface) as shown schematically in Fig. $3[5,9]$. The equilibrium at these triple points is determined as shown in Fig. 3 by a simple force balance that defines the groove angle following eq. (1). Note from the microstructure 
shown in Fig. 1 that in the as-deposited films, the in-plane grain boundaries are almost orthogonal to the interphase interface (i.e., $\theta=90^{\circ}$ ), resulting in an energetically unfavorable configuration. Thus, it is expected that elevated temperature annealing will result in diffusive mass transport along boundaries so as to establish an equilibrium groove angle at the triple points. If the depth of the groove is greater than the layer thickness, then the grooving will split the layers creating lamellae termination points which can then begin to spheroidize. Hence, the critical event for the multilayered film stability is the grooving kinetics and how quickly the layers are split and this is discussed next.

For multilayered thin films, the grooving kinetics may be described by the following equation derived by Josell and Spaepen [5]:

$\mathrm{x}^{3}=\left(\mathrm{D}_{\mathrm{L}} \mathrm{h}+\mathrm{D}_{\mathrm{B}} \delta\right) \frac{\gamma \Omega \mathrm{t}}{\mathrm{hkT}}$

where $\mathrm{x}$ is the groove depth, $\mathrm{D}_{\mathrm{L}}$ is the lattice diffusion, $D_{B}$ is the grain boundary diffusivity, $\delta$ is the boundary thickness, $\gamma$ is the interface free energy, $\Omega$ is the atomic volume, $\mathrm{k}$ is the Boltzman constant, $\mathrm{T}$ is the annealing temperature and $\mathrm{t}$ is annealing time. Using $\mathrm{D}_{\mathrm{B}} \delta$ for $\mathrm{Nb}$ $=6 \times 10^{-16} \mathrm{~mm}^{3} / \mathrm{s}$ and $\mathrm{D}_{\mathrm{L}}=3 \times 10^{-21} \mathrm{~mm}^{2} / \mathrm{s}$ at $973 \mathrm{~K}$, $\gamma_{\mathrm{Cu} / \mathrm{Nb}} \approx 1 \mathrm{~J} / \mathrm{m}^{2}, \mathrm{~h}=75 \mathrm{~nm}, \mathrm{t}=3600 \mathrm{~s}$ and $\Omega=1.8 \mathrm{x}$ $10^{-20} \mathrm{~mm}^{3}, \mathrm{x}$ is obtained as $\approx 30 \mathrm{~nm}$. This compares quite well with the experimentally observed groove depths of $\approx 35-40 \mathrm{~nm}$ shown in Fig. 2(b). Since grooving requires mass transport of both $\mathrm{Cu}$ and $\mathrm{Nb}$, the kinetics is controlled by the slower of the two $(\mathrm{Nb})$. Note that at the anneal temperatures, $\mathrm{D}_{\mathrm{B}}>\mathrm{D}_{\mathrm{L}}$ for $\mathrm{Nb}$. Thus, lattice diffusion of $\mathrm{Nb}$ can be ignored.

The above model explains only part of the microstructural evolution shown in Fig. 2, i.e., the grooving, and not the offset or shear of layers along a vertical plane at triple points. We propose a mechanism (Fig. 5) to interpret the observed morphological stability of the $\mathrm{Cu}-\mathrm{Nb}$ multilayers. Consider the case shown in Fig. 5(a) where the corresponding grains I and II in $\mathrm{Cu}$ and $\mathrm{Nb}$ have the low energy $\{110\} \mathrm{Nb} / /\{111\} \mathrm{Cu}$ interface but not the interface segment 'ab' where grain $\mathrm{I}$ in $\mathrm{Cu}$ and grain $\mathrm{II}$ in $\mathrm{Nb}$ form the interface. Such an initial structure is consistent with Fig. 1 since $\mathrm{Cu}$ and $\mathrm{Nb}$ do not have the same in-plane grain size. At elevated temperatures, in-plane grain boundary migration occurs in the direction of arrows to remove the high-energy segment 'ab'. Note that the grain boundary migration of $\mathrm{Cu}$ will be significantly faster than that of $\mathrm{Nb}$. The in-plane grain boundary migration leads to the situation shown in Fig. 5(b) where an (a)

(b)

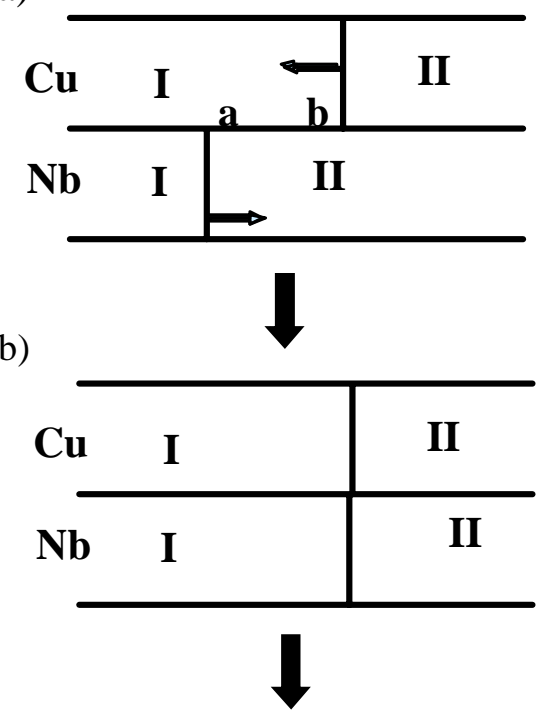

(c)

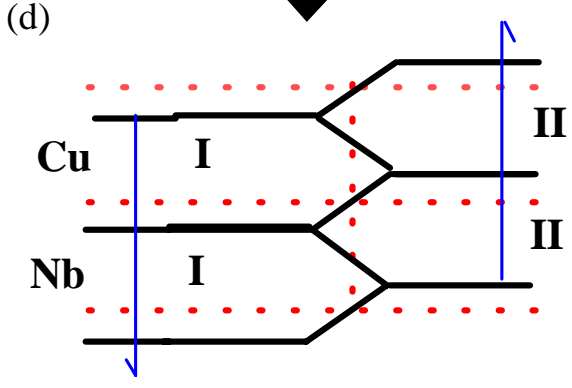

Fig.5 Schematic of the morphological evolution observed in nano-scale $\mathrm{Cu}-\mathrm{Nb}$ multilayers upon elevated temperature annealing. 
energetically unfavorable quadruple point has been created as the sideways migration leads to an overlap of grain boundaries (compare Fig. 2(a) with Fig. 5(b)). As a result, the unstable quadruple point breaks into two triple points (Fig. 5(c)). Diffusive mass transport at both of these triple points along the directions marked by arrows in Fig.5(c) will occur to establish equilibrium groove angles, resulting in a final configuration shown in Fig. 5(d) where the layers are sheared across a vertical plane formed by the overlap of sideways migrating grain boundaries. The final structure (compare Fig. 2(b) with Fig. 5(d)) is found to be extremely stable due to the sheared layers with equilibrium groove angles at triple points acting as "anchor" points and preventing further grain growth or layer splitting. This "anchored" structure resulted after $700{ }^{\circ} \mathrm{C} / 1$ hour annealing (Fig. 2(b)). Annealing at temperatures higher than $700{ }^{\circ} \mathrm{C}$ (Fig. 2(c)) or for longer times at $700{ }^{\circ} \mathrm{C}$ to 60 hours (results to be presented in a future article) did not result in any further morphological instability. Thermal stability of these multilayers as a function of the bilayer period is being studied and will be presented in a future article.

\section{SUMMARY}

Sputter-deposited nanoscale $\mathrm{Cu}-\mathrm{Nb}$ multilayers exhibit excellent microstructural stability and hardness retention following vacuum annealing at temperatures up to $800{ }^{\circ} \mathrm{C}$. Thermal grooving at grain boundaries was observed after 700 and $800{ }^{\circ} \mathrm{C}$ annealing. The Josell-Spaepen [5] diffusion model, using $\mathrm{Nb}$ grain boundary diffusion as rate controlling, describes the grooving kinetics. However, thermal grooving did not result in layer pinch-off. Rather, the shear of layers across the grooving triple points resulted in an "anchored" structure resistant to further morphological instability. A mechanism for the evolution of this stable microstructure is proposed. The hardness retention, in spite of coarsened in-plane grains, suggests that the hardness is primarily determined by the spacing of the $\mathrm{Cu} / \mathrm{Nb}$ interfaces that remained unchanged after annealing.

\section{ACKNOWLEDGEMENTS}

This work is supported by the Office of Basic Energy Sciences, Department of Energy. Authors acknowledge discussions with F. Spaepen, J.D. Embury, J.P. Hirth, T.E. Mitchell, P. Anderson and M. Nastasi.

\section{REFERENCES}

1. B.M. Clemens, H. Kung and S.A. Barnett, MRS Bulletin, 24, 20, February (1999).

2. A. Misra and H. Kung, Advanced Engineering Materials, 217, April (2001).

3. J.C. Malzahn Kampe, T.H. Courtney and Y. Leng, Acta Metall., 37, 1735 (1989).

4. G. Sharma, R.V. Ramanujan and G.P. Tiwari, Acta Mater., 48, 875 (2000).

5. D. Josell and F. Spaepen, MRS Bulletin, 24, 39, February (1999).

6. R.G. Hoagland, T.E. Mitchell, J.P. Hirth and H. Kung, Phil Mag A, 2002, in press.

7. Lord Rayleigh, Proc. London Math. Soc., 10, 4 (1878).

8. N. Sridhar, J.M. Rickman and D.J. Srolovitz, Acta Mater., 45, 2715 (1997).

9. A.C. Lewis, A.B. Mann, D. van Heerden, D. Josell and T.P. Weihs, Mat. Res. Soc. Symp. Proc., 652 (2001), in press. 